КУДРЯШОВА А.И.

ассистент кафедры природообустройства

Поволжский государственный технологический университет

(Россия, г. Йошкар-Ола)

\title{
ФАКТОРНЫЙ АНАЛИЗ ВЗАИМОВЛИЯНИЯ ЭКОНОМИЧЕСКИХ И КАДАСТРОВЫХ ПОКАЗАТЕЛЕЙ СУБЪЕКТОВ РОССИИ
}

\begin{abstract}
По данным земельного кадастра Российской Федеращии приведены закономерности бинарных отношений между количеством земельных участков, численностью населения и валового регионального продукта. Доказано, что влияние общей площуади, количество районов и кадастровых кварталов субъектов малозначимо. Для сравнения разньх групп факторов предложен коэффициент коррелятивной вариации. По рейтингу среди влияющих переменных на первом месте оказалось население, на втором - количество земельных участков. Как показатель на первом месте также находится население, на втором - валовой региональный продукт субъектов РФ. Максимальный коэффициент корреляции 0,9095 получила эконометрическая закономерность влияния численности населения на количество земельных участков.
\end{abstract}

Ключевые слова: территория, население, валовой региональный продукт, районы, кадастровые квартала, земельные участки, закономерности.

Выявление экономических закономерностей между факторами земельного кадастра, охраны окружающей среды и публичной карты позволяет лучше управлять развитием территорий и прогнозировать эффективные меры по улучшению землепользования.

В продолжение исследований [1-6] в данной статье показана методика факторного анализа в совокупности экономических и кадастровых показателей на примере территорий субъектов Российской Федерации.

Нами составлены интегрированные данные земельного кадастра, экономических и кадастровых показателей субъектов Российской Федерации из докладов «О состоянии и использовании земель в Российской Федерации в 2011 году» и «О состоянии и об охране окружающей среды Российской Федерации в 2012 году». Данные по количество районов, кадастровых кварталов и земельных участков по субъектам федерации были получены из публичной карты http://maps.rosreestr.ru/PortalOnline/ . 
По шести выбранным параметрам был проведен факторный анализ.

В таблице 1 приведены коэффициенты корреляции закономерностей у всех бинарных распределений.

Таблица 1 - Корреляционная матрица и рейтинг факторов

\begin{tabular}{|c|c|c|c|c|c|c|c|c|}
\hline \multirow{2}{*}{$\begin{array}{c}\text { Факторы } \\
\text { как объясняющие } \\
\text { переменные } x\end{array}$} & \multicolumn{6}{|c|}{ Факторы - показатели $y$} & \multirow{2}{*}{\begin{tabular}{|c|} 
Сумма \\
коэф. \\
корр.
\end{tabular}} & \multirow{2}{*}{$\begin{array}{c}\text { Рей- } \\
\text { тинг } \\
I_{x} \\
\end{array}$} \\
\hline & $\begin{array}{c}S, \\
\text { т. га }\end{array}$ & $\begin{array}{c}N, \\
\text { т. чел. }\end{array}$ & $\begin{array}{c}V, \\
\text { млрд. } \mathbf{p}\end{array}$ & $\begin{array}{l}n_{P}, \\
\text { Шт. }\end{array}$ & $\begin{array}{l}\mathrm{n}_{\text {КК }}, \\
\text { ШТ. }\end{array}$ & $\begin{array}{l}\mathrm{n}_{3 \mathrm{y}}, \\
\text { шт. }\end{array}$ & & \\
\hline Итого земель $S$ т. га & 1 & 0,0233 & 0,1868 & 0,1673 & 0,1341 & 0,0046 & 1,5161 & 6 \\
\hline Население $N$, т. чел. & 0,1139 & 1 & 0,8871 & 0,8442 & 0,6495 & 0,9095 & 4,4042 & 1 \\
\hline ВРП $V$, млрд. руб. & 0,2225 & 0,8754 & 1 & 0,7122 & 0,4832 & 0,8553 & 4,1486 & 4 \\
\hline Кол-во районов $n_{P}$, шт. & 0,0452 & 0,8152 & 0,7707 & 1 & 0,5972 & 0,8096 & 4,0379 & 3 \\
\hline Кол-во кад. кв. $\mathrm{n}_{\text {Кк }}$, шт. & 0,2660 & 0,6407 & 274 & 0 , & 1 & 373 & 15 & 5 \\
\hline Кол-во зем. уч. $\mathrm{n}_{\text {зу }}$,шт. & 0,0770 & 0,9057 & 571 & 0 & 0,6746 & 1 & 23 & 2 \\
\hline Сумма коэф. коррел. & 1,7246 & 4,2603 & 4,2291 & 4,1817 & 3,5386 & 4,2163 & 22,1506 & - \\
\hline Рейтинг $I_{y}$ & 6 & 1 & 2 & 4 & 5 & 3 & - & 0,6153 \\
\hline
\end{tabular}

Коэффициент коррелятивной вариации свойств физического объекта исследования равен отношению общей суммы коэффициентов корреляции к квадрату от количества факторов. По данным таблицы 1 коэффициент коррелятивной вариации будет равен $22,1506 / 6^{2}=0,6153$. Это достаточно высокий показатель функциональной связности элементов системы.

По рейтингу среди влияющих переменных на первом месте оказалось население, на втором - количество земельных участков. Как показатель на первом месте также находится население субъектов РФ, на втором - валовой региональный продукт.

Далее был проведен выбор сильных бинарных отношений при коэффициенте корреляции более 0,7 .

Уточненная корреляционная матрица приведена в таблице 2.

Таблица 2 - Корреляционная матрица с коэффициентом корреляции $r \geq 0.7$

\begin{tabular}{|l|c|c|c|c|}
\hline \multirow{2}{*}{$\begin{array}{c}\text { Факторы } \\
\text { как объясняющие } \\
\text { переменные } x\end{array}$} & \multicolumn{4}{|c|}{ Факторы - показатели $y$} \\
\cline { 2 - 5 } & $\begin{array}{c}N, \\
\text { т. чел. }\end{array}$ & $\begin{array}{c}V, \\
\text { млрд. }\end{array}$ & $\begin{array}{c}n_{P}, \\
\text { шт. }\end{array}$ & $\begin{array}{c}\mathrm{n}_{\text {зу }}, \\
\text { шт. }\end{array}$ \\
\hline Население $N$, т. чел. & & 0,8871 & 0,8442 & 0,9095 \\
\hline ВРП $V$, млрд. руб. & 0,8754 & & 0,7122 & 0,8553 \\
\hline Кол-во районов $n_{P}$, шт. & 0,8152 & 0,7707 & & 0,8096 \\
\hline Кол-во зем. уч. $\mathrm{n}_{\text {зу }}$,шт. & 0,9057 & 0,8571 & 0,8179 & \\
\hline
\end{tabular}


Строки и столбцы (того земель $S$, количество кадастровых кварталов $\mathrm{n}_{\text {кк}}$ ) исключаются. Сверхсильная связь наблюдаются между параметрами «Количество земельных участков $\mathrm{n}_{\text {зу }}$ и «Население $N$ ». Всего сильных связей получилось 12 шт. (табл. 3).

Таблица 3 - Параметры трендов поведения субъектов РФ по земельным участкам

\begin{tabular}{|c|c|c|c|c|c|c|c|c|c|}
\hline \multirow{3}{*}{$\begin{array}{c}\text { Пара- } \\
\text { метр } \\
x\end{array}$} & \multicolumn{8}{|c|}{$y_{m}=y_{m 1}+y_{m 2}$} & \multirow{3}{*}{$\begin{array}{c}\text { Коэф. } \\
\text { корр. } \\
r\end{array}$} \\
\hline & \multicolumn{4}{|c|}{$y_{m 1}=a_{1} x^{a_{2}} \exp \left(-a_{3} x^{a_{4}}\right)$} & \multicolumn{4}{|c|}{$y_{m 2}=a_{5} x^{a_{6}} \exp \left(-a_{7} x^{a_{8}}\right)$} & \\
\hline & $a_{1}$ & $a_{2}$ & $a_{3}$ & $a_{4}$ & $a_{5}$ & $a_{6}$ & $a_{7}$ & $a_{8}$ & \\
\hline \multicolumn{10}{|c|}{ Изменение население $N$, т. чел. } \\
\hline$V$, млрд. р. & 0,66594 & 0 & $-0,83080$ & 0,29484 & 32,97001 & 0,64889 & 0 & 0 & 0,8754 \\
\hline$n_{P}$, шт. & 0,075080 & 3,23593 & 0,041267 & 1 & 0 & 0 & 0 & 0 & 0,8152 \\
\hline $\mathrm{n}_{\text {зу }}$, Шт. & 423,55672 & 0 & 0 & 0 & 0,0025887 & 0 & 0 & 0 & 0,9056 \\
\hline \multicolumn{10}{|c|}{ Изменение ВРП $V$, млрд. руб. } \\
\hline$N$, т. чел. & 111,09673 & 0 & $-0,00040495$ & 1 & $1,74402 \mathrm{e}-6$ & 2,602870 & 0,00058458 & 1 & 0,8870 \\
\hline$n_{P}$, Шт. & 0,12957 & 2,51303 & 0,025949 & 1 & 0 & 0 & 0 & 0 & 0,7707 \\
\hline $\mathrm{n}_{\text {зу }}$, Шт. & 116,08332 & 0 & 0 & 0 & $7,53069 \mathrm{e}-5$ & 1,15587 & 0 & 0 & 0,8572 \\
\hline \multicolumn{10}{|c|}{ Изменение количества районов $n_{P}$, шт. } \\
\hline$N$, т. чел. & 37,19970 & 0 & 0,0092651 & 1 & 0,12334 & 0,791040 & 0,00010406 & 1 & 0,8442 \\
\hline$V$, млрд. р. & 7,85289 & 0 & 0,00038450 & 1 & 0,50869 & 0,714350 & 0,00045341 & 1 & 0,7122 \\
\hline $\mathrm{n}_{\text {зу }}$, ШТ. & 8,71397 & 0 & 0 & 0 & 0,017466 & 0,56277 & 0 & 0 & 0,8179 \\
\hline \multicolumn{10}{|c|}{ Изменение количества земельных участков $\mathrm{n}_{\text {зу }}$,шт. } \\
\hline$N$, т. чел. & 169,35077 & 0 & $2,97712 \mathrm{e}-5$ & 1 & 109,80480 & 1,12283 & 0 & 0 & 0,9095 \\
\hline$V$, млрд. р. & 47205,732 & 0 & 0 & 0 & 1017,3122 & 0 & 0 & 0 & 0,8553 \\
\hline$n_{P}$, шт. & 254,14165 & 2,13232 & 0,00010660 & 1,96489 & 0 & 0 & 0 & 0 & 0,8096 \\
\hline
\end{tabular}

По данным таблицы 3 всего закономерностей будет $6^{2}=36$. Тогда доля сильных связей составит $12 * 100 / 36=33,3 \%$ или 1/3. Бинарных связей всего равно 36 - 6 = 30. По убыванию коэффициента корреляции расставим 12 бинарных отношений следующим образом: 1) 0,9095- $\mathrm{n}_{3 \mathrm{y}}=f(N)$; 2) 0,9056 - $N=f\left(n_{3 y}\right)$; 3) $0,8870-V=f(N)$; 4) $0,8754-N=f(V)$; 5) 0,8572 $\left.\left.\left.V=f\left(n_{3 y}\right) ; 6\right) \quad 0,8553-\mathrm{n}_{3 \mathrm{y}}=f(V) ; 7\right) \quad 0,8442-n_{\mathrm{P}}=f(N) ; 8\right) 0,8179-$ $\left.\left.\left.n_{P}=f\left(n_{3 y}\right) ; 9\right) 0,8152-N=f\left(n_{P}\right) ; 10\right) 0,8096-n_{3 y}=f\left(n_{P}\right) ; 11\right) 0,7707-$ $\left.V=f\left(n_{P}\right) ; 12\right) 0,7122-n_{P}=f(V)$.

Заметно, что закономерности расставлены попарно (рис.1. и рис. 2), как прямые и обратные формулы. Параметры уравнений этих сильных закономерностей приведены в таблице 3. 


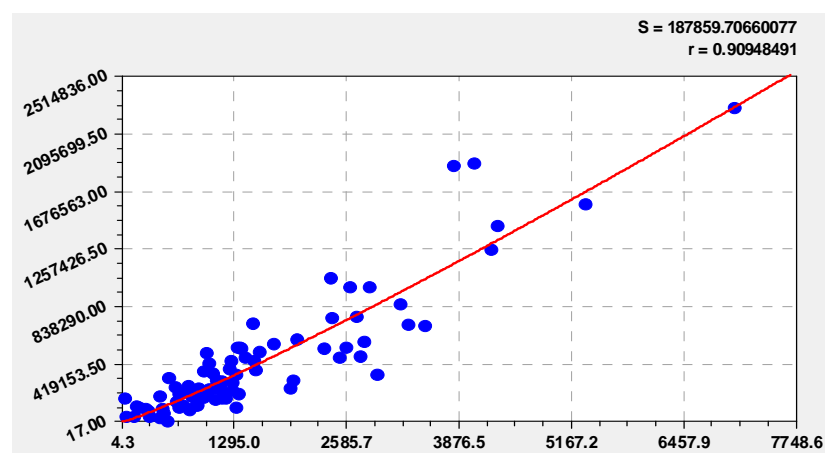

1) $0,9095-\mathrm{n}_{3 \mathrm{y}}=f(N)$

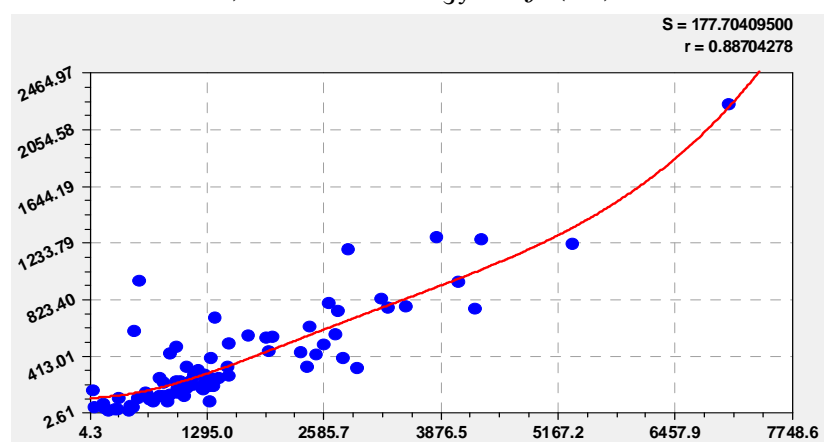

3) $0,8870-V=f(N)$

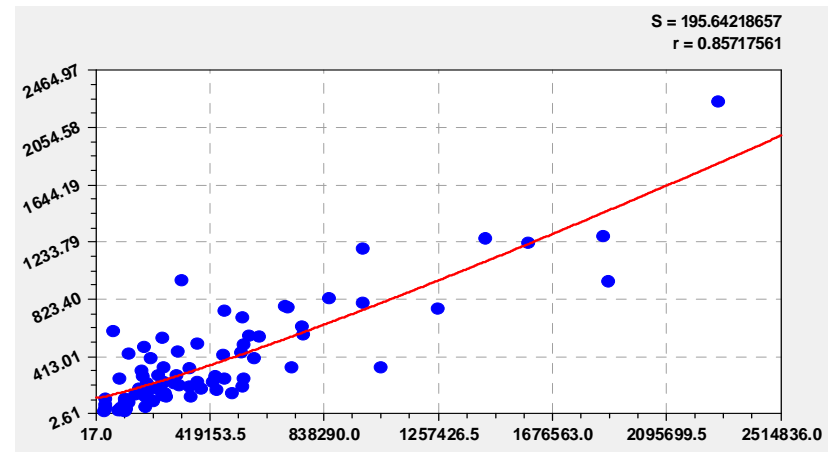

5) $0,8572-V=f\left(n_{3 y}\right)$

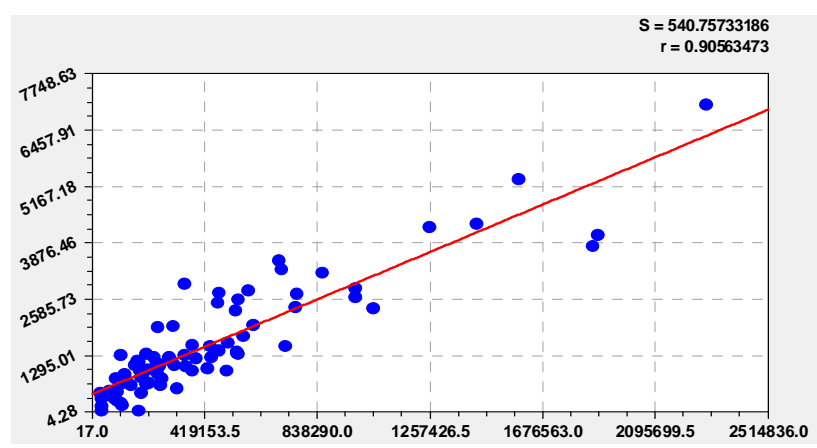

2) $0,9056-N=f\left(n_{3 V}\right)$

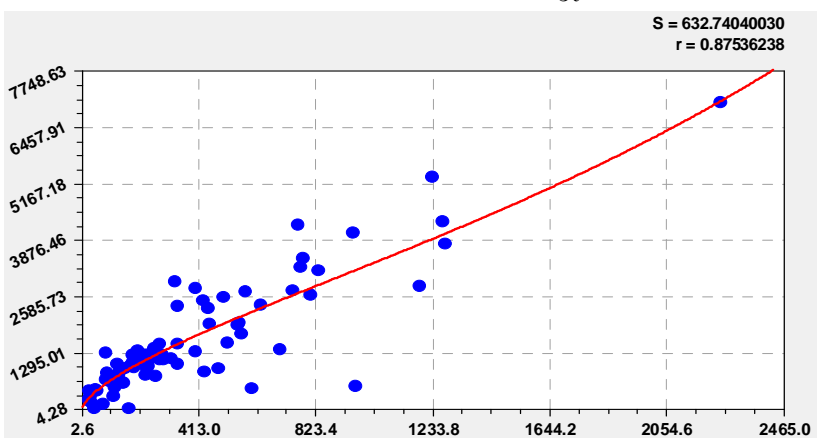

4) $0,8754-N=f(V)$

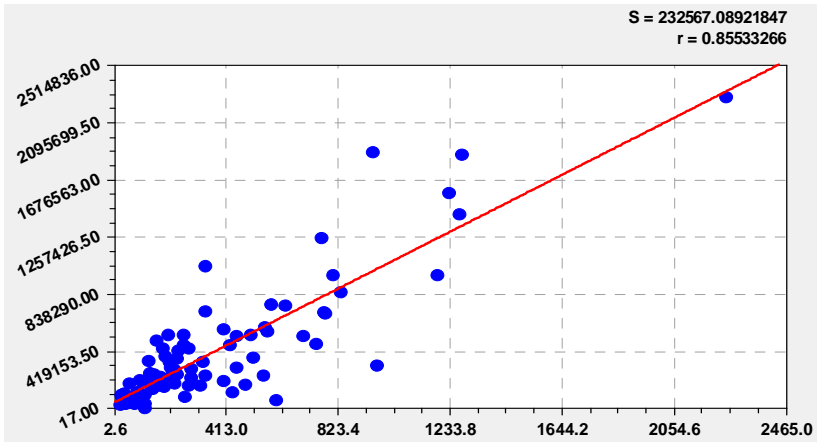

6) $0,8553-\mathrm{n}_{3 \mathrm{y}}=f(V)$

Рис. 1. Графики закономерностей взаимовлияния численности населения, количества земельных участков и валового регионального продукта

Первая группа из шести бинарных отношений показывает взаимные связи численности населения, количества земельных участков и валового регионального продукта, а вторая группа - дополнительно количества районов.

Таблица 4 - Параметры трендов поведения субъектов РФ по земельным участкам

\begin{tabular}{|l|c|c|c|c|c|c|c|c|}
\hline $\begin{array}{c}\text { Пара- } \\
\text { метр } x\end{array}$ & $\begin{array}{c}\text { Пока- } \\
\text { затель } y\end{array}$ & $a_{1}$ & $a_{3}$ & $a_{4}$ & $a_{5}$ & $a_{6}$ & $a_{7}$ & $\begin{array}{c}\text { Коэф. } \\
\text { корр. } r\end{array}$ \\
\hline$N$, т. чел. & $\mathrm{n}_{\text {зу }}$ & 169,35077 & $2,97712 \mathrm{e}-5$ & 1 & 109,80480 & 1,12283 & 0 & 0,9095 \\
\hline $\mathrm{n}_{\text {зу }, \text { шт. }}$ & $N$ & 423,55672 & 0 & 0 & 0,0025887 & 0 & 0 & 0,9056 \\
\hline$N$, т. чел. & $V$ & 111,09673 & $-0,00040495$ & 1 & $1,74402 \mathrm{e}-62,602870,00058458$ & 0,8870 \\
\hline$V$, млрд. p. & $N$ & 0,66594 & $-0,83080$ & 0,29484 & 32,97001 & 0,64889 & 0 & 0,8754 \\
\hline $\mathrm{n}_{\text {зу }, \text { шт. }}$ & $V$ & 116,08332 & 0 & 0 & $7,53069 \mathrm{e}-5$ & 1,15587 & 0 & 0,8572 \\
\hline$V$, млрд. p. & $\mathrm{n}_{\text {зу }}$ & 47205,732 & 0 & 0 & 1017,3122 & 0 & 0 & 0,8553 \\
\hline
\end{tabular}



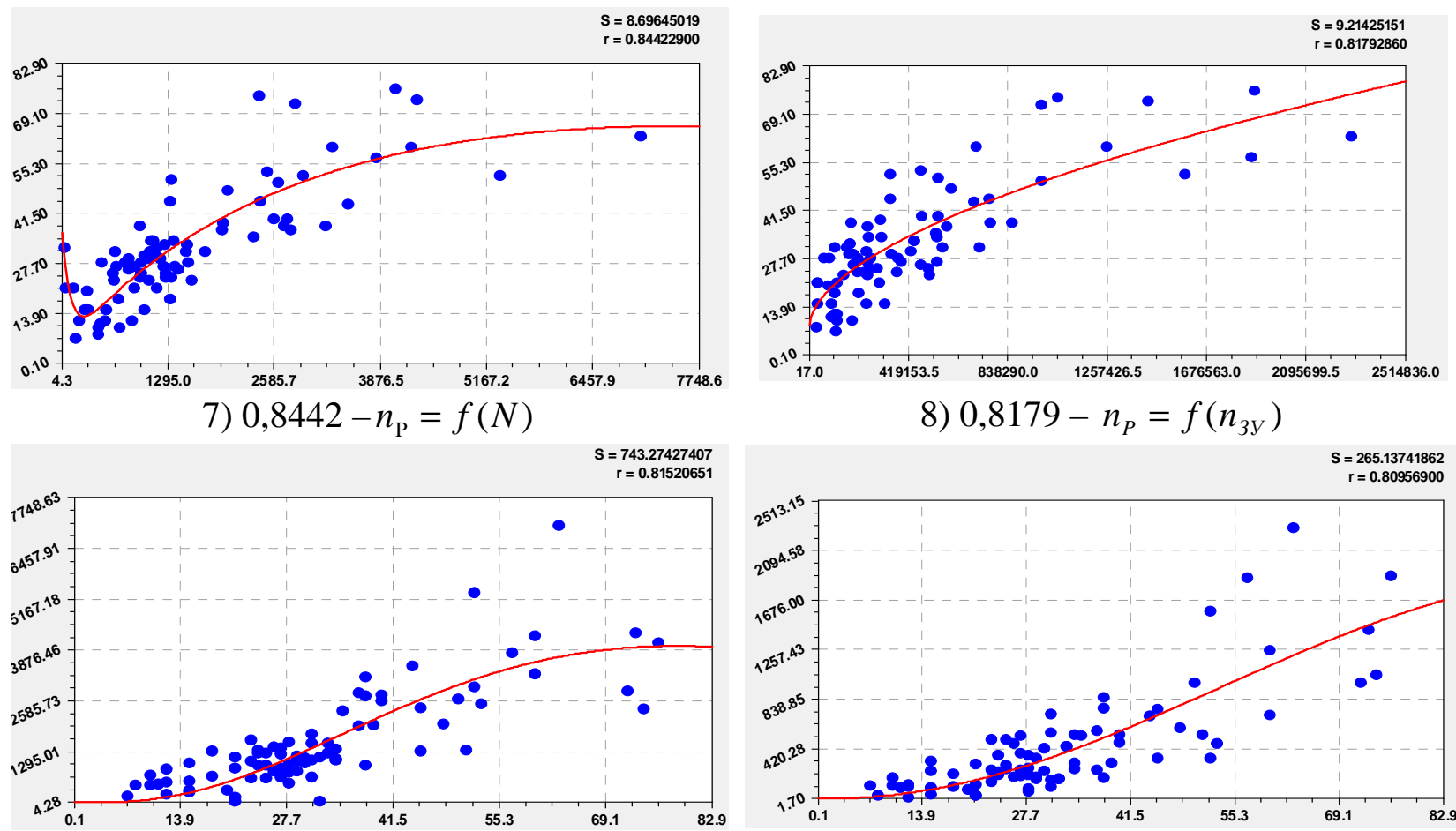

8) $0,8179-n_{P}=f\left(n_{3 y}\right)$

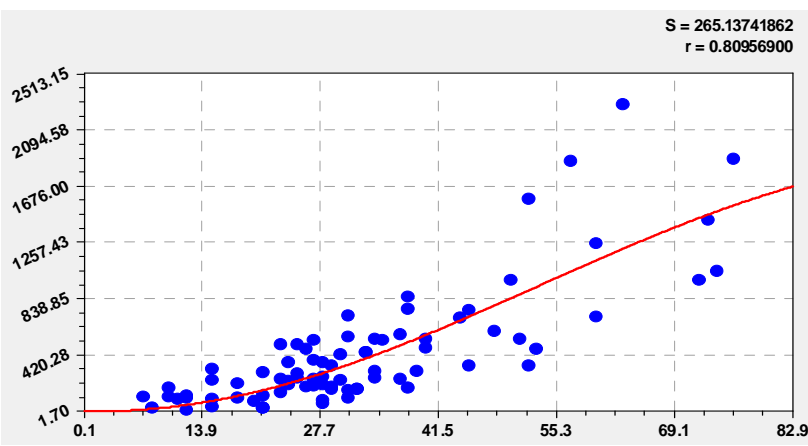

9) $0,8152-N=f\left(n_{P}\right)$

10) $0,8096-n_{3 y}=f\left(n_{P}\right)$
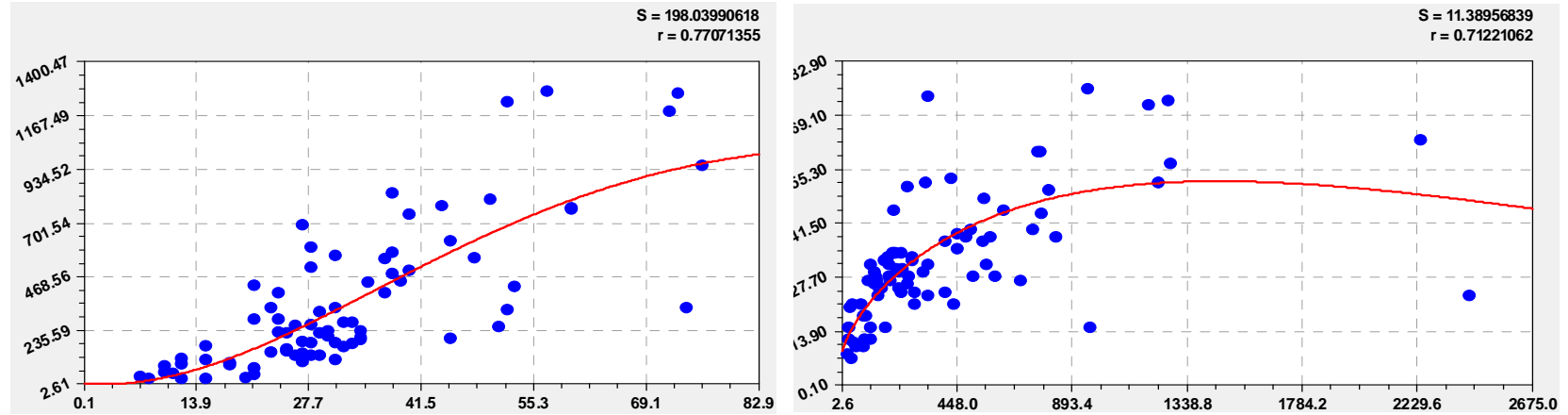

11) $0,7707-V=f\left(n_{P}\right)$

12) $0,7122-n_{P}=f(V)$

Рис. 2. Графики закономерностей взаимовлияния численности населения, количества земельных участков, районов и валового регионального продукта

Из интегрированных данных земельного кадастра, экономических и кадастровых показателей субъектов Российской Федерации. Была выбрана группа экономических и кадастровых показателей в разрезе субъектов Российской Федерации. Из этой группы в таблице 4 после факторного анализа исключились общая площадь $S$, количество районов $n_{P}$ и количество када-

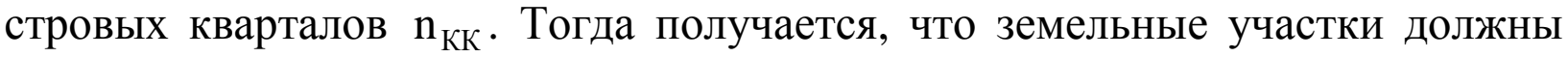
соответствовать классификации ООН по глобальному агроэкологическому зонированию.

Среди показателей в таблице 4 на втором и третьем местах оказались численность населения и валовой региональный продукт, как результат дея- 
тельности этого населения субъекта Российской Федерации. Этот факт указывает на то, что земельные участки являются главными средствами производства для любых отраслей экономики. А по классификации ООН травяной покров, кустарники и древостои являются основными элементами растительного покрова на земельных участках.

\section{Список литературы}

1. Кудряшова А.И. Методика картографических измерений элементов растительного покрова городской зоны застройки многоэтажными жилыми домами // Фундаментальные исследования. № 11 (часть 7) . 2015. С. 13321337.

2. Кудряшова А.И., Мазуркин П.М. Рейтинг древостоев и кустарников городской среды по лучшему кадастровому кварталу // Успехи современного естествознанию №1. 2016 С. 120-125.

3. Мазуркин П.М., Кудряшова А.И. Рейтинг земельных участков города с кустарником // Успехи современного естествознания. №1. 2016. С. 126131.

4. Мазуркин П.М., Кудряшова А.И., Фадеев А.Н. Вейвлет-анализ распределений центров кадастровых кварталов города // Землеустройство, кадастр и мониторинг земель. 2015. №8. с. 61-70.

5. Мазуркин П.М., Кудряшова А.И., Фадеев А.Н. Распределения кадастровых кварталов по подзонам жилой зоны города // Землеустройство, кадастр и мониторинг земель. 2016. №1. с. .

6. Мазуркин П.М., Кудряшова А.И. Рейтинг участков с деревьями на кадастровых кварталах города // Успехи современного естествознания. №12. 2015. C. $127-132$. 